\title{
Two Varieties of Literary Imagination: Metaphor, Fiction, and Thought Experiments
}

\author{
ELISABETH CAMP
}

$\mathrm{R}$ ecently, philosophers have discovered that they have a lot to learn from, or at least to ponder about, fiction. Many metaphysicians are attracted to fiction as a model for our talk about purported objects and properties, such as numbers, morality, and possible worlds, without embracing a robust Platonist ontology. In addition, a growing group of philosophers of mind are interested in the implications of our engagement with fiction for our understanding of the mind and emotions: If I don't believe that Anna Karenina exists, can I really pity her, or hope or desire that she extricate herself from her tragic situation? And why is there no "morality fiction," analogous to science fiction?

I suspect that philosophers have been especially comfortable thinking about fiction because it seems, at least prima facie, to employ the imagination in a way that conforms to a standard model of the mind. Specifically, contemporary philosophers tend to think of imagination as a form of mental pretense. Mental pretense can take two main forms: a cognitive attitude of supposing a set of propositions to be true (make-believe) or else an experiential state of imaging a scenario as if it were before one (imaging). Much of our pretense intertwines the cognitive and experiential modalities, of course. But both share a crucial common feature: all of one's imaginative effort is invested in pretending that certain contents obtain. In this sense, we can understand imagination as the "offline" simulation of actual beliefs and perceptions (and perhaps other attitudes as well), where we analyze these in the normal way, as states individuated by their attitude and representational content.

While I share the burgeoning interest in fiction, I want to suggest that we also have a lot to learn from poetry, and in particular from poetic metaphor. I will argue

(C) 2009 Copyright the Authors. Journal compilation (C) 2009 Wiley Periodicals, Inc. 
that metaphors call for a different species of imaginative activity, often described in terms of "framing" or "seeing-as" (Black 1962, Davidson 1978, Moran 1989), which is at least as concerned with how one imagines a certain content as with what one imagines. Once we notice the role of imaginative "seeing-as" in metaphor, we can see that related perspectival effects also play a role in our engagement with fiction, and even philosophy. The result, I hope, is a richer understanding of minds in general, and of imagination in particular.

\section{§1. METAPHOR AS FICTION}

I begin by discussing the view that a single imaginative mechanism underwrites both metaphorical and fictional interpretation. Kendall Walton (1993) is the primary proponent of this view, although others, such as David Hills (1997), have also endorsed it. Walton claims that a metaphor "implies or suggests or introduces or calls to mind a (possible) game of make-believe" $(1993,46)$ : a game in which the sentence uttered would be true. The content of the speaker's assertion, in turn, "amounts to the claim that certain circumstances obtain, namely, the circumstances that would make it fictional that she speaks truly if, fictionally, she asserts the literal truth of what she says" $(1993,43)$. The idea here is that by speaking metaphorically, the speaker pretends to assert the sentence that she actually utters, and thereby evokes a game of make-believe within which a literal assertion of that very sentence would be true. The objects in the real world that she is talking about, and which prompt her utterance, are "props" in this game of make-believe; and the speaker's ultimate claim is that those objects do in fact possess certain propertiesthose that make them apt props for the evoked game. So, for example, when Anne says to her colleagues,

(1) Bill is a bulldozer,

she is asking her hearers to play, or at least to recognize, a game of pretense for which Bill is a prop, and in which an utterance of (1) would be literally true; Anne thereby claims that Bill really possesses the properties that make him a good prop for this game. In this way, Walton extends to metaphor the same general model of imagination that he has deployed so successfully in the analysis of fiction.

Of course, Walton doesn't deny that there is any distinction between fiction and metaphor. The difference, he thinks, lies in our orientation to the game of make-believe: in the purpose for which we do this imagining. In ordinary fiction, our interest lies the content we imagine, for its own sake; we use props from the real world, such as sticks and novels, just in order to facilitate the pretense that we're cops and robbers, or hearing about the travails of a woman named "Anna Karenina." In the case of metaphor, by contrast, our primary interest lies in the prop itself. For instance, when we hear (1), we engage in a pretense about Bill only insofar as we need in order to recognize what features he might actually have that would underwrite (1)'s fictionality relative to that game.

Walton himself is fairly circumspect about which games of make-believe are generated by specific metaphorical utterances, and about what makes a prop apt 
for a particular game. ${ }^{1}$ However, given that he holds that an utterance like (1) evokes a game of make-believe in which the sentence literally construed is true, it seems that at a minimum he must accept that metaphorically interpreting (1) involves imagining, or at least evokes the possibility of imagining, a game in which Bill is a bulldozer. ${ }^{2}$ In his own neo-Waltonian account of metaphor, David Hills (1997, 147-48) explicitly embraces this model:

In saying "Juliet is the sun," Romeo pretends that she just plain is exactly that. This pretense of his calls attention to allegedly real circumstances that allegedly make it possible and allegedly make it worth engaging in. In particular, the pretense calls attention to various allegedly real features of Juliet that allegedly qualify her to play the sun's part. This is how Romeo's pretense concerning Juliet serves to say something about what Juliet is actually like. (The "allegedly" talk is ugly, I admit, but it's there for good reason: we need to be able to account for metaphorical falsity.)

Thus, we appear to have a view on which metaphorical interpretation calls for the same basic sort of pretense as we would engage in if confronted with the same sentence presented as a fiction. ${ }^{3}$ Further, Walton also claims that his account can make good sense of the long-standing intuition that metaphors "frame," "illuminate," or lead us to see one thing "as" or "in terms of" another $(1993,47)$. A metaphor offers us a new perspective on an object, he thinks, by getting us to realize that it can be used as a prop in the game of pretense that it evokes.

I agree with Walton and Hills that metaphorical utterances claim ${ }^{4}$ that their subjects possess features which are brought to our attention by evoking or cultivating a certain sort of imaginative "game." I also agree that utterances in the general ballpark of metaphor can be used to evoke games of make-believe, and

1. He also abjures any ambition to explain all of the utterances we call "metaphors," on the grounds that these may not form a unified class. While this may well be right, it makes it difficult to offer counterexamples to his view. I take it, though, that the examples I discuss are sufficiently paradigmatic that they should be covered by any account of metaphor.

2. Though see the qualifications on p. 114, below.

3. Hills $(1997,148)$ continues the quote above by suggesting that metaphor calls for a "particular imaginative practice, a particular game of make believe, wherein states of the world would inspire and mandate very specific imaginings in very specific ways." So perhaps Hills would object to my claim that he assimilates metaphor to the sort of make-believe involved with fiction. I will argue in $\$ 2$ that metaphor does not in the first instance employ pretense at all, and so that the relevant game of make-believe must be very particular indeed if it is to underwrite metaphorical interpretation. Other theorists have explicitly embraced a basic equivalence between the interpretation of metaphor and fiction. For instance, Steven Yablo (2001) adopts a Waltonian model of metaphor in advocating "figuralism" about mathematics. Figuralism-the view that talk in a certain domain is metaphorical-is Yablo's favored version of fictionalism. We should be fictionalists about some domain X, Yablo says, if "when we examine X-language in a calm and unprejudiced way, it turns out to have a whole lot in common with language that is fictional on its face. If one now asks which elements of everyday language are fictional on their face, the answer is the figurative elements" $(2001,87)$, where he later equates figurativeness to metaphor $(2001,93)$.

4. Or put forward with other illocutionary forces: like most theorists, I restrict my attention here to the assertive case, though I do not think this simplification is without theoretical cost. 
that they can thereby provide us with new perspectives on their subjects. However, I believe that metaphors generally involve a different sort of imaginative game than make-believe, and that utterances which do evoke make-believe are not usually metaphors. While these other utterances may get us to "see things in a new light," they do not generate the "seeing-as" that is distinctive of metaphor.

An initial indication that something is wrong here is that not all metaphors are literally false, or even trivially true:

(2) Moscow is a cold city.

(3) There are storm clouds on the horizon.

(4) Jesus was a carpenter.

all accurately (or at least potentially accurately, in [3]) describe substantive states of affairs. Thus, at least in these cases metaphorical interpretation must involve something other than pretending that the sentence literally expressed is true: Because these sentences already are true, there would be no imaginative work left to do. ${ }^{5}$ But it doesn't seem that we interpret these metaphors any differently than their absurd and trivial cousins; indeed, we may not even notice that a metaphor like (2) or

(5) No man is an island.

is literally true until someone points this out. But if that is right, then we want to know what process is common to interpreting substantively true, trivial, and false sentences metaphorically.

A more interesting way of identifying what's wrong with a pretense view is to see that it does accurately describe a quite different phenomenon: just-so stories. Just-so stories are not presented as being actually true, but rather as fictions that are so apt it's as if they are-or should be-true at a deeper level. For instance, I might describe an acquaintance's personality by saying,

(6) It's as if Jane had a puppy who died when she was little, and she's still convinced it was her fault,

knowing full well that no such thing ever happened to Jane. Rather, I want you to pretend that it_ "just plain exactly that," as Hills puts it—did happen to her. My purpose in getting you to pretend this is prop-oriented: I want to draw attention to features of Jane as she really is, such as her expectation that everything will always go wrong, her apologetic incompetence, and her obsequiousness with superiors.

Further, I hope that pretending that (6) is true will give you an open-ended "perspective" on Jane. Walton doesn't say what he takes a perspective to be, but I think a perspective provides an intuitive, holistic principle for organizing our

5. Or at least, the imaginative work must involve something other than seeing what features are drawn to our attention by pretending that the sentence literally expressed is true. It is especially odd that Hills (1997) advocates a view that has difficulty with metaphors like (2) through (4), since he draws attention to the phenomenon of metaphors that are not merely "twice-true," in Ted Cohen's (1976) terms, such as (2) and (3), but "twice-apt," such as (4). I discuss twice-apt metaphors like (4) in Camp (2008). 
thoughts about some topic. ${ }^{6}$ It organizes those thoughts by imposing a complex structure of relative prominence on them, so that some features stick out in our minds while others fade into the background, and by making some features especially central to explaining others. A perspective often also imposes certain evaluative attitudes and emotional valences on its constituent features. Finally, a perspective doesn't just present us with a complex thought, to the effect that a host of basic-level features are related in a higher-order structure. Rather, it gives us a tool for thinking. Being a "tool for thought" means at least two things here. First, a perspective helps us to do things with the thoughts we have: to make quick judgments based on what's most important, to grasp intuitive connections, and to respond emotionally, among other things. And second, it provides us with a "way to go on," incorporating new thoughts about the focal topic and often about related topics as well. ${ }^{7}$

So, it looks like an utterance of (6) should count as a metaphor by Walton's and Hills's lights: it introduces a game of pretense, according to which Jane "just plain is exactly" as she is described by the sentence uttered, with the purpose of inducing a perspective on that game's focal prop in order to draw attention to features of it as it is in reality. However, intuitively just-so stories like (6) seem quite different from metaphors like (1) - precisely because the intended imaginative activity, and the resulting understanding, is so directly connected to the proposition literally expressed. In interpreting (6), you imagine that Jane "just plain is exactly that," and this draws attention to the very features of actual Jane that underwrite that pretense. In interpreting (1), by contrast, the relation between the sentence uttered and the intended imaginative state is considerably more indirect. If you really pretended that Bill was a bulldozer, you'd end up with a wildly inappropriate interpretation, on which he was enormous and clanking and consumed a lot of diesel. Taking (1) as an occasion for Waltonian pretense-that is, taking it as a just-so story-draws attention to different features of Bill than those Anne was claiming him to possess when she uttered (1). Thus, even if we ultimately decide to classify (6) as a metaphor, we need an account of metaphorical interpretation which explains the imaginative contours and results of our ordinary interpretation of more paradigmatic metaphors like (1).

\section{§2. TWO IMAGINATIVE PROJECTS}

We can get a better understanding for the difference between pretense and metaphorical "seeing-as" by contrasting the two ways of approaching a single sentence. Consider, for example,

6. Much of what Walton does say about perspectives or "framing" (1993) suggests that he would accept this characterization, at least in its broad outlines.

7. I discuss perspectives in Camp (2003) and in an unpublished manuscript, "Perspectives in Imaginative Engagement with Fiction"; in the latter, I distinguish between "aspects," as topicspecific structuring principles, and "perspectives," as general dispositions to structure our thoughts in certain ways. I suppress that distinction here. 
(7) I am Anna Karenina.

Simply put, pretending (7) to be true involves transforming myself imaginatively so that I become Anna Karenina; while construing (7) as a metaphor involves imaginatively employing Anna as a "lens" to structure my understanding of myself.

More specifically, pretending (7) to be true involves imagining me being Anna Karenina, by imaginatively altering the content of who I am: endowing myself with properties that Anna possesses which I lack, and erasing properties of mine that she doesn't have, in order to transform me into "just plain exactly" Anna, or as close to it as I can achieve. As part of this process, I might imagine being married to a bland and unreflective government official, having to attend and host an endless stream of high society events, and being caught between an abiding love for my child and a consuming passion for my lover in a society where divorce means losing all access to my child. More generally, in order to imagine one person or thing being something else-my husband being Jack the Ripper, say-I may need to imagine them possessing traits which bear no interesting resemblance to those they actually possess. My imaginative project may not be all-encompassing. In pretending to be Anna, for instance, I might not even attempt to imagine myself attending the opera dressed in a fancy gown amidst the rest of aristocratic Russian society. But to be successful, I must transform myself in my imagination so that I take on many of Anna Karenina's important features. In this sense, Anna forms the goal of my imaginative efforts, and I am a prop for achieving that goal.

On the other hand, if I take (7) as a metaphor, then I use Anna to structure my understanding of myself, as I "just plain exactly" am. Rather than imaginatively endowing me with Anna's important properties (or vice versa), a metaphorical interpretation uses Anna to filter or frame my characterization of myself. ${ }^{8}$ This involves matching important features of Anna's to features of mine that are similar to hers in some significant respect. Some of these similarities may be quite immediate: I might be just as impetuous or headstrong as she is, for instance; or I might possess those same qualities but to a lesser degree. But other similarities may be merely structural. For instance, I might decide that Anna's conflict between her love for her son and her love for Vronsky mirrors my own struggle to reconcile parental devotion and professional ambition; if so, the thought of having a lover need not enter into my self-understanding for me to endorse the metaphorical truth or aptness of (7). Similarly, if I find an echo of Anna's aimless season in Italy in my own time between college and graduate school, then this itself constitutes a respect in which the metaphor is true or apt, and the fact that I spent that time in

8. "Characterization" is my technical term for the complex network of thoughts associated with an object, on which metaphorical interpretation (along with much other intuitive thinking) operates. To a rough first approximation, characterizations are conceptions or stereotypes. I offer a fuller discussion of metaphorical interpretation in my (2003). In my (2008), I discuss the differences between metaphor and two other rhetorical devices that also produce perspectives: juxtapositions and "telling details." 
Seattle rather than Venice is no mark against the analogy. ${ }^{9}$ When I do find matches within myself for important features of Anna's, then those matched features take on a greater prominence in my characterization of myself. They may also come to be imbued with the explanatory power and emotional valences that the corresponding features play in my characterization of Anna. For instance, my being headstrong may now seem more dangerous than liberating, and also more central to explaining a host of my decisions and actions. The overall result of this matching process is a restructured understanding of myself, one which highlights, connects, and colors my Anna-like features while downplaying the rest.

With these sketches of pretense and metaphorical construal in hand, we can contrast the two imaginative activities more theoretically. Both projects produce a kind of identification between me and Anna, but they bridge the gap between us in very different ways. The first major difference involves what we, following John Searle (1969) and Samuel Levin (1988), might call the interpretive "direction of fit": which of us is the focus and goal of imaginative activity, and who is mere means. In the case of pretense, an actual object or situation $X$ serves as a prop for imagining something else, $Y$; while in metaphor $Y$ functions as a tool for understanding $X$, as it actually is. The second difference lies in the mechanism by which the two projects achieve their "fit" between the two objects or situations: where pretense endows $X$ with the very properties that are most importantly possessed by $Y$, metaphorical construal highlights properties of $X$ which are merely similar in some significant way to $Y$ 's important properties.

A third difference is that metaphorical construal involves a kind of "twofoldness" that pretense lacks. Richard Wollheim $(1980,213)$ describes the experience of seeing a picture as involving "simultaneous attention to what is represented and to the representation, to the object and to the medium." A similar phenomenology occurs with metaphorical construal: We are simultaneously aware of both the focal subject (me, Bill) and the representing frame (Anna, bulldozers), as distinct entities. But this awareness of their distinctness doesn't just not undermine, it often heightens, the richness of their imaginative interaction. Further, just as with pictorial seeing, the two components are united into a single cognitive state, of thinking of the one entity through our conception or characterization of the other. This is the distinctive phenomenon of "seeing $X$ as $Y$ " which so many people have taken to be characteristic of metaphor.

By contrast, pretense involves no such doubleness. When we employ an object as a prop in a game of make-believe, it is precisely a prop: a mere means to an imaginative end. Differences between its actual properties and those ascribed to

9. What counts as an important feature of the framing characterization will vary by cognitive context. Notice that because metaphorical construal starts with the most important features of the framing object, and seeks matches to them in our characterization of the focal subject, a metaphorical utterance of a sentence like "Surgeons are butchers" will generate a different interpretation than its inverse, "Butchers are surgeons." Together, the context-sensitivity and directionality of the matching process undermine the traditional criticism, which Walton echoes, that similarity accounts of metaphor are vacuous because "everything is like everything, and in endless ways" (Davidson 1978, 39). 
it within the pretense are usually obstacles to be overcome: for instance, it may be easier to play cops-and-robbers with a realistic toy gun in your hand than a simple stick. ${ }^{10}$ More importantly, employing an object as a prop within the pretense seems to be incompatible with simultaneously attending to it as the object it actually is. For instance, while pretending that I am seeing a green slime oozing toward me, I cannot also attend to the movie screen and the flickering lights upon it as such, to the screeching violins in the soundtrack as such, or even to the pattern of jump cuts between the depicted slime and the terrified bystanders. Insofar as I am actively engaged in the pretense, my attention must remain within the fictional world, on the slime's approach toward me and those who are fictively near me; the screen, violins and jump cuts can enter into my attention only as contributors to that fiction.

So far, I have argued that interpreting (7) metaphorically and pretending it to be true are significantly different sorts of imaginative activity, with different mechanisms, goals, and phenomenology. ${ }^{11}$ What implications can we draw from this for Walton's claim that metaphor involves prop-oriented pretense more specifically? It is difficult to tell. Walton consistently suggests that metaphors merely evoke, rather than inviting full participation in, games of make-believe. He also explicitly rejects the claim that prop-oriented pretense involves imagining things of one kind to be things of another kind, because he thinks this is often difficult or impossible to do: he thus appears to deny that metaphorical interpretation always involves pretending that $X$ "just plain is exactly" $F$, as Hills maintains. ${ }^{12}$ Instead, Walton proposes that seeing-as is often "a matter of taking things of one kind to prescribe imaginings about things of another kind" $(1993,48)$.

Each of these moves weakens the link between metaphor and pretense as we intuitively understand it (and as Walton himself understands it in his analysis of fiction); and Walton doesn't offer much in the way of a positive characterization to fill in the gap. Given what we have said so far, though, it seems that he faces a dilemma. He can insist that prop-oriented pretense works in the same basic way as pretense more generally, differing primarily in its ultimate point or purpose; but then it seems he must deny the intuitive differences between metaphor and pre-

10. Moran $(1994,83)$ points out that an artwork's formal aspects often enhance rather than detract from our emotional engagement with it, even as they disrupt its realism. I think this is important, and helps to show how fiction itself involves more than just make-believe, as I discuss in $\$ 3$. Walton (1990) also addresses this phenomenon at several points.

11. These differences in the direction, mechanism, and phenomenology of pretense and metaphorical construal presumably generate differences in the neural mechanisms implementing them. Thus, I predict that the Walton-Hills hypothesis that metaphor is a form of prop-oriented pretense is empirically falsifiable, although it would be a challenge to develop a sufficiently refined experimental paradigm.

12. For instance, he says, "It is not easy to see how one might imagine a corporation to be (literally) healthy or sick" $(1993,49)$. Later, Walton $(2000,77)$ suggests that it may merely be fictional that the speaker asserts some true proposition with her utterance, where that proposition need not be the literal meaning of the sentence uttered, and indeed there need be no particular proposition about which it is fictional that the speaker asserts it. However, Walton offers no further guidance about what the relation between the sentence uttered and what is fictionally asserted, or more generally what is fictional relative to the game, might be. In conversation, he has suggested that there are no general principles to be given. 
tense that I have pointed out. Or he can agree that prop-oriented pretense does differ significantly from ordinary pretense in the respects I've identified. But then this puts pressure on him to accept something like a traditional account of metaphorical interpretation, of the sort I sketched above, as a way of spelling out what "prop-oriented make-believe" amounts to. ${ }^{13}$

Insofar as we can use the fictive interpretation of sentences like (7) as an intuitive guide to what's involved in prop-oriented make-believe, it seems that prop-oriented pretense does work in the same basic way as ordinary pretense. ${ }^{14} \mathrm{I}$ might well decide to pretend that I am Anna Karenina in order to see what it reveals about me, and specifically to see what features of mine would underwrite that pretense: as an exercise in psychotherapy or method acting, for instance. But attending to those features as features of myself, as opposed to as features of imagined-Anna, seems to be something I can only do after I have left the pretense, or else by oscillating between the pretense and a disengaged, analytic perspective. Thus, prop-oriented pretense still seems to lack twofoldness. ${ }^{15}$ It also seems likely to draw attention to different properties of the object. In particular, metaphorically seeing myself as Anna is likely to end up highlighting features of mine that Anna herself lacks, but which are somehow similar to those she possesses. When that happens, those highlighted features of myself may well be features which the pretense of being Anna would need to ignore. For instance, if Anna's conflict between her love for her son and for Vronsky finds a match in my struggle to reconcile parental devotion and professional ambition, then this match relies on a feature of myself-being a professional woman-which Anna importantly lacks, and so which would need to be downplayed, if not erased entirely, within the pretense that I am Anna.

I think these considerations are enough to suggest a fairly systematic distinction between the two imaginative projects of pretense and metaphorical construal. Indeed, I think they point to a more general distinction, between two levels at

13. In particular, insofar as prop-oriented make-believe does involve taking things of one kind to prescribe imaginings about things of another kind, rather than involving imagining things of one kind to $b e$ things of the other kind, the uttered sentence provides less direct guidance about what the relevant fictional game might be. Instead, the interpretive focus shifts to establishing the appropriate mapping between facts about each of the two kinds of thing, thereby rendering the "pretense" account more like a traditional view which maps features from one domain onto another.

14. In conversation, Walton suggested that my pretending to be Anna Karenina is a case of fantasy rather than prop-based pretense (where "prop-based pretense" may itself be either propor content-oriented), insofar as the content of my imagining is not constrained by features that I already possess. This sort of imaginative freedom would seem to apply to many games we intuitively think of as involving props, however. For instance, many games of cops-and-robbers which use sticks as guns pretend that the guns have features which are not grounded in features of the sticks: that they are six-shooters, say. The scope of properly prop-based pretense may thus be more restricted than we would intuitively have thought.

15. At some points, Walton appears to accept that full immersion in the pretense is incompatible with simultaneous attention to the prop as it is in actuality $(1990,15 ; 275-77)$, although he also seems to think that most prop-oriented pretense (whether in the service of metaphor or for some other purpose) does not require full immersion. See Nanay (2004) for an argument that Waltonian pretense also fails to capture the twofoldness of pictorial representation. 
which imagination can operate. ${ }^{16}$ Pretense, I suggest, involves the manipulation of content: altering what is so, in order to produce a new world in the imagination. By contrast, metaphorical construal manipulates the mode of presentation of a fixed content: It imaginatively alters how we structure and color our thoughts about what is so. If we want catchphrases with which to label these different projects, we might say that fiction imagines a metaphysical transformation of its prop, while metaphor invites a conceptual transfiguration of its topic. As our discussion of just-so stories like (6) and the fictive interpretation of (7) show, metaphor is not the sole means for producing conceptual transfiguration: Pretense can also alter our perspective on how something actually is, and thereby get us to "see it in a new light." But when it does, this comes as a consequence of the imaginative manipulation of contents into alternative possibilities, rather than as an inherent component of that imaginative activity itself.

\section{§3. IMAGINATION IN ACTION: APPLICATIONS TO LITERATURE}

In this section, I apply the distinction between pretense and metaphor to the interpretation of literature. It would be natural to assume that the two imaginative activities are associated with different literary genres: that fiction asks us to imagine alternative possibilities, while lyric poetry involves a metaphorical, conceptual transfiguration of actuality. In fact, though, both genres regularly make use of both species of imaginative activity - and not merely because fiction itself often employs metaphorical language.

The first point is that literary fictions employ the same cognitive structures involved in metaphorical construal, and that they can also manipulate those structures in order to transfigure our existing concepts. The simplest way in which fictions can alter our understanding of the real world arises as a direct result of the pretense itself: I might, for instance, gain a more intimate appreciation for the anguish of orphanhood, or for the attractions of gambling or being a bully, by empathizing with characters who undergo those emotions (cf. Currie 1995, 1997; Kieran 2003; Novitz 1987). By broadening our range of experience, fiction can provoke us to notice and respond empathetically to similar people and situations as we encounter them in real life; and this awareness may in turn lead us to reconfigure our moral and psychological theories more generally. Here, art is functioning as a proxy for life, allowing us to acquire experiential knowledge without the pain, risk, and time investment-and sometimes, metaphysical impossibility—-that they normally entail.

Most theorists would accept that fictions can alter our sense of reality by expanding the range of contents we have available to reflect upon. But fictions can also change our minds in a more systematic way as well. So far, I've mainly been criticizing philosophers like Walton for failing to distinguish pretending-true from

16. Moran $(1994,86)$ likewise contrasts "imagination" in the sense of make-believe about fictional truths with "imaginativeness," understood as "the ability to make connections between various things, to notice and respond to the network of associations that make up the mood or emotional tone of a work." More generally, many of my points echo themes of his (1989) and (1994). 
seeing-as. But there's another criticism to be made as well: Actual literary fiction requires more than just pretending that certain propositions are true, in either a cognitive or perceptual modality. An author or narrator also presents the facts of the fictional world from a certain perspective, which she expects us to share. ${ }^{17}$ If a reader scrupulously pretends true all of the propositions that the author explicitly makes fictional, but assigns them wildly different structures of relative importance, explanatory connection, and emotional and evaluative valence than the author intended, then she has significantly misinterpreted the fiction. A serial killer who relishes American Psycho as a joyful romp, for instance, or a pedophile who laments that Humbert Humbert is brought to justice in Lolita-or even a reader who focuses all her imaginative energy on the slaves in Gone with the Wind-has gotten something importantly wrong about those novels, even if they've gotten all the constituent events just right.

In the most interesting cases, the author's intended interpretation differs from the one we would naturally adopt were we to encounter the same set of characters and situations for ourselves. This is one important reason why we value fictions: They enable us to "get inside the head" of an alternate personality, to experience in an intimate, first-person way what it's like for someone else to meet the world around them (cf. Currie 1997). Further, this experience may end up altering our own perspective on the real world. What begins as a temporary exercise in perspectiveshifting may unwittingly cause a modification of our ongoing dispositions to notice, interpret, and respond to related situations as we encounter them in reality. Indeed, authors often intend for us to "export" the fiction's perspective back to the real world (Gendler 2000). Tolstoy, for instance, doesn't just want us to pity Anna Karenina for the duration of our engagement with the novel; he also wants us to sympathize with the challenge of reconciling personal passion with societal expectation in the real world, and to accept the difficulty, perhaps even the futility, of satisfying one's deepest desires. Thus, complex literary fictions, like their shorter just-so cousins, can produce conceptual transfiguration: They can get us to see the world "in a new light," shifting our sense of what is important, what sorts of people and possibilities are out there, and how we ought to respond to them.

Turning to poetry, we find that often enough it does use metaphor in order to provide insight into how things really are. Shakespeare's (1609/1997) Sonnet 73 is a classic example of this:

That time of year thou mayst in me behold When yellow leaves, or none, or few, do hang Upon those boughs which shake against the cold, Bare ruin'd choirs, where late the sweet birds sang.

In me thou see'st the twilight of such day

As after sunset fadeth in the west,

17. For discussion of perspectives in fiction, see my unpublished manuscript "Perspectives in Imaginative Engagement with Fiction"; see also especially Moran (1994) and Gendler (2000). Note that authors are not always fully authoritative about their own works (or intentions): Blake famously claimed that Milton was of the devil's party without knowing it. 
Which by and by black night doth take away,

Death's second self, that seals up all in rest.

In me thou see'st the glowing of such fire

That on the ashes of his youth doth lie,

As the death-bed whereon it must expire

Consumed with that which it was nourish'd by.

This thou perceivest, which makes thy love more strong,

To love that well which thou must leave ere long.

Shakespeare here uses three linked metaphors, of moments within increasingly short temporal cycles-winter, twilight, and a dying fire-as frames for aging and death. As we pass into each successively shorter cycle, approaching the moment of death, the quality of the light becomes dimmer, the colors become more intense, and the imagined scene becomes smaller, more intimate, and more focused (Booth 1969). Within and across each of the stanzas, we highlight features in our characterizations of aging and death that are analogous to features of the framing situations: Aging, like the coming of winter, the twilight of the day, and the burning down of a fire, is a natural and inevitable moment following on from more abundant, energetic ones. Crucially, we also transfer onto aging and death many of the experiential and emotional responses that we associate with those framing situations: the feeling of being cold and surrounded by darkness; quiescence, sadness and nostalgia; but also acceptance and awareness of what lies ahead. Taken as a whole, the poem's metaphors help to focus our attention on a fact which is at once too enormous, too obvious, and too painful to confront outright, by providing us with cognitive and emotional structures associated with situations that are more concrete, imagistic, and experiential. Further, as Jenefer Robinson (2005, 222-27) argues, the poem's imagery, its formal structure, and the intellectual puzzle of comprehending those metaphors all act as "coping mechanisms," enabling us to reflect upon the reality of aging and death through a complex frame that is at once apt and aesthetically pleasurable.

But clearly not all poetry fits this Shakespearean mode. Taking Shakespeare's sonnet as a canonical use of the poetic imagination helps to identify what is so unsettling about Charles Simic's (1977) "Eyes Fastened with Pins":

How much death works,

No one knows what a long

Day he puts in. The little

Wife always alone

Ironing death's laundry.

The beautiful daughters

Setting death's supper table.

The neighbors playing

Pinochle in the backyard

Or just sitting on the steps

Drinking beer. Death, 
Meanwhile, in a strange
Part of town looking for
Someone with a bad cough,
But the address somehow wrong,
Even death can't figure it out
Among all the locked doors...
And the rain beginning to fall.
Long windy night ahead.
Death with not even a newspaper
To cover his head, not even
A dime to call the one pining away,
Undressing slowly, sleepily,
And stretching naked
On death's side of the bed.

Here Simic takes up the same impulse to render something as amorphous and incomprehensible as death more concrete. But in place of the traditional image of Death in a hooded friar's sackcloth with a sickle, Simic presents death as a stereotypical overworked family man in contemporary America. ${ }^{18}$ In marked contrast to Shakespeare's sonnet, the poem's language is resolutely literal, and it invites us to pretend that "just plain exactly" the situation it describes is true. In particular, where many death poems, like Shakespeare's, employ metaphors to help us know how to feel about death, Simic's presentation is absurdly matter-of-fact: The poem's primary emotional engagement involves empathizing with death - the very thing that is so terrible and incomprehensible in the first place-as an ordinary bloke having a bad day on the job. Simic's poem thus provides us with a clear demonstration that poetry can call for pretense and can do so in the absence of metaphor.

One might take the poem as just an exercise in surreal fantasy; and indeed, a significant part of the poem's interest lies in how Simic plays out the conceit's literal details, for their own sake. Such a reading is especially tempting becauseagain, unlike Shakespeare-Simic focuses so little on what death's "work" really is, and because we cannot fully conceive what it would be for death-the cessation of all biological and conscious activity-to behave and feel as the character in the poem does. Against this reading, we have the general intuition that poetry is supposed to provide some insight into reality. More significantly, the poem's title offers a jarring reminder of death's brutal effects, and the insistent drumbeat of the word "death" continually forces us back into the attempt to imagine that death itself is engaged in these activities. A significant part of the poem's aim, I think, is precisely to force us into this imaginative conundrum, and thereby to throw us back into terrifying incomprehension, by dislodging the sorts of comforting interpretive frames offered by poems like Shakespeare's. Still, along the way a few global matches may begin to emerge between the described scenario and our own relation to death. In particular, the poem highlights how much death there is always

18. Neil Gaiman's Sandman exploits a similar conceit, albeit in a very different register. 
around us, on every block and income bracket. In turn, it also highlights the absurdity of our own insistence on carrying on our ordinary quotidian activitiesironing, setting the table, sipping a beer on the stoop-in the face of this terrifying proximity to death. Simic thus upends the traditional exhortation to dispense with banalities (live life to the fullest since death is right around the corner) by inviting us to imagine a banal existence for death itself, struggling to make all his appointments. Ultimately, though, that inversion implicitly reinforces the traditional contrast between daily life and the horrifying fact of our mortality.

Thus, where Shakespeare's sonnet is thoroughly metaphorical and focuses on comprehending the reality of aging and death, Simic's poem is resolutely literal and focuses on pretending an absurdly surreal alternative to be real. Other poems involve a more fluid interplay between pretense and metaphor. Consider William Stafford's (1977) poem "A Story That Could Be True":

If you were exchanged in the cradle and your real mother died without ever telling the story then no one knows your name, and somewhere in the world your father is lost and needs you but you are far away.

He can never find how true you are, how ready. When the great wind comes and the robberies of the rain you stand on the corner shivering. The people who go by you wonder at their calm. They miss the whisper that runs any day in your mind, "Who are you really, wanderer?" and the answer you have to give no matter how dark and cold the world around you is: "Maybe I'm a king."

Like Simic's poem, this poem also clearly engages in a kind of fictive pretense; and with just one clear exception ("the robberies of the rain"), its language also appears to be entirely literal. It opens by presenting an epistemic, rather than metaphysical possibility: as the title says, a story that could be true, not one that could have been true. And part of its rhetorical urgency comes from the presentation of this possibility as a live option-one that is actually true for all you know. But with the introduction of the "great wind" and "robberies of the rain," this fairy-tale epistemic possibility morphs into a darker counterfactual, or at least a future contingent one: You do presumably know, after all, that you are not currently standing on a corner shivering and lonely. And with that shift, the story also begins to cast a metaphorical 
light on your actual self: You are like a homeless person, insofar as you don't know who you really are; and you are like someone who is ignorant of your ancestry in being ignorant of your own true values, and of how you want to live. The poem's final line then serves a double function. Within the pretense, it holds out the fairy-tale possibility that your suffering is the trial that will reveal you to be "true" and "ready" for assuming your father's crown. But that possibility in turn serves as a metaphor for how to live your actual life. Roughly, if you live as if you really might be a king — as if, at some deeper level, you should be "just plain exactly" a kingthen you may ultimately transform yourself into someone who is genuinely kingly.

I believe, then, that Stafford's poem — and to a lesser extent, Simic's — achieve a metaphorical, twofold perspective by employing a literally described alternative possibility as a frame for reality. This is itself a surprising result, since we normally think of metaphoricity as a trope of speech. Other poems do employ metaphorical language, but do so in a way that is so "deeply meant" that their full interpretation requires engaging in something like pretense. To see how this might be, we can again contrast two different construals of the same sentence. Suppose, first, that while you and I are hiking in the hills, we encounter a lakeshore filled with springtime flowers, and I utter:

(8) Look at those daffodils dancing in the breeze.

You agree that the wind is causing the daffodils to toss about in a fetching manner, and we walk on. My utterance is literally false but successfully draws your attention to the fact that the flowers are bouncing rhythmically. Now suppose that you encounter a similar sentence at the end of the first stanza of Wordsworth's (1804/ 1967) poem "I Wandered Lonely as a Cloud":

I wandered lonely as a cloud

That floats on high o'er vales and hills,

When all at once I saw a crowd,

A host, of golden daffodils;

Beside the lake, beneath the trees,

Fluttering and dancing in the breeze.

Continuous as the stars that shine

And twinkle on the milky way,

They stretched in never-ending line

Along the margin of a bay:

Ten thousand saw I at a glance,

Tossing their heads in sprightly dance.

The waves beside them danced; but they

Out-did the sparkling waves in glee:

A poet could not but be gay,

In such a jocund company:

I gazed-and gazed-but little thought

What wealth the show to me had brought: 
For oft, when on my couch I lie, In vacant or in pensive mood,

They flash upon that inward eye

Which is the bliss of solitude;

And then my heart with pleasure fills,

And dances with the daffodils.

We can interpret the sentence in the same basic way in this context as well. If so, we will conclude that Wordsworth has described a pretty if fairly familiar natural vista by using a string of florid "poetic" metaphors. On this reading, what Wordsworth really meant was just that while he was on an aimless walk, he saw a lot of daffodils bouncing in the breeze next to a sparkling lake, which perked him up, and that now he likes to recall this pretty scene while sitting on his sofa. Encountering a similar poem in a junior-high literary magazine, we might conclude that it was sweet but trite. ${ }^{19}$

On the other hand, we can take the poem more seriously, and assume that Wordsworth's words offer the closest possible approximation to what he really meant, so that no other linguistic means would have served to express his experience. In this case, rather than just identifying a relatively superficial respect in which the flowers' motion is like dancing, we try to imagine that the daffodils possess as many properties that are as closely analogous to those of dancers as we can. Crucially, this will include imagining them to possess features we would normally dismiss as beyond the bounds of what someone might plausibly mean. I might pretend, for instance, that the daffodils are filled with the "sap of life;" that their movement is a response to the "music of the spheres;" and that they take positive pleasure in their massed companionship. If I read the entire poem in this fashion, then I may ultimately end up cultivating a fairly radical vision of Romantic vitalism: as Levin $(1979,123)$ puts it, "a view of the universe in which a single, undifferentiated spirit course[s] through all of nature, uniting human beings and the objects of their natural surroundings." ${ }^{20}$ In both the deeply-meant and the flat-footed readings, then, we picture the daffodils doing the sort of thing they might actually do: bouncing rhythmically. What differentiates the two readings is our perspective on them and their motion: our explanation for it, the larger class of activities of which we take it to be a manifestation, and our emotional and experiential response to it.

19. Cf. Cleanth Brooks (1947, 169): "For example, the last two lines of [Wordsworth's] 'Intimations' ode-'To me the meanest flower that blows can give/ Thoughts that do often lie too deep for tears'-when taken in isolation ... make[] a statement which is sentimental if taken in reference to the speaker and one which is patent nonsense if taken with a general reference. The man in the street (of whom the average college freshman is a good enough replica) knows that the meanest flower that grows does not give him thoughts that lie too deep for tears; and if he thinks about the matter at all, he is inclined to feel that the person who can make such an assertion is a very fuzzy sentimentalist."

20. Levin (1988) uses Wordsworth, as I have, as an example of the way that poetic metaphors can reverse the standard "direction of fit" of interpretive construal in the service of a broader conceptual transfiguration. 
Thus, the interpretation of such deeply meant metaphors demands an interesting interplay between conceptual transfiguration and metaphysical transformation. Ordinary metaphorical interpretation seeks matches within the focal subject for just the most important features in the framing characterization, and is happy to match them with any type of salient similarity. But with "deeply meant" metaphors, we seek as many matches as possible, and we try to match those features as closely as possible. The more matches we can find, and the more we can match those features by identity or at least close qualitative similarity rather than just structural analogy, the closer we come to thinking of the subject as doing or being "just plain exactly" as the framing characterization says; and in turn, the less palpable our sense of twofoldness becomes. The more we succeed in doing this, the more the metaphorical starts to verge on the literal.

In order to achieve all of these close matches between the two domains, however, we are likely to need to do more than just restructure and color our pre-established characterizations of the focal subject: We may need to substantively transform how we take that subject to be. This might happen in one of two ways. First, we might decide that the subject really does possess properties that we had previously neglected or outright denied. In the current example, we might have a genuine conversion to vitalism. Or more likely, second, we might just pretend that it has those properties: in this case, by going along with Wordsworth's vitalism for the duration of the poem. To the extent that the features we pretend the subject to possess are only analogous to features of the framing object, our interpretation remains metaphorical. I think this captures our reading of most of Wordsworth's poem: We merely pretend something that Wordsworth really believed-that the daffodils possess certain properties, like overflowing with life force, which are themselves still only analogous to features of dancers dancing. To the extent that we do pretend that the subject possesses the very features exemplified by the framing object, though, our interpretation becomes more fictive, and more literal.

Arthur Danto $(1981,172)$ claims that "the greatest metaphors of art" are those in which "an artwork becomes a metaphor for life, and life is transfigured." Danto has in mind here the sort of metaphor exemplified in (7), in which I see myself as Anna Karenina. In these cases, he says, "the spectator identifies himself with the attributes of the represented character: and sees his or her life in terms of the life depicted." We've now seen several further examples of Danto's lifetransfiguring metaphors of art, in which the content of a work of art serves as the frame for understanding some analogous situation, or even life in general. Simic describes an absurdly unreal scenario which then points to the absurdity of our own insistence on doing just those things that the poem's characters do. Stafford tells a fictional story that could be real, which he then offers as the frame for a metaphorical understanding of our own actual situation. In both of these cases, we come to see our lives in terms of a fictional scenario which is itself described in entirely literal terms. By contrast, Wordsworth employs apparently conventional metaphors to describe a real scene, but uses them in a way that is so deeply meant that their full interpretation pushes us toward pretense, with the result that metaphorical twofoldness begins to break down, and the language becomes nearly literal. When artworks do become metaphors for reality in these various ways, it is 
neither just the described content itself, nor just the artwork's general perspective, which frames our understanding; rather, we see our own lives through that content as interpreted from that perspective.

\section{§4. IMAGINATION IN PHILOSOPHY}

I want to conclude by briefly exploring the role played by the two imaginative activities I have identified within the practice of philosophy. Pretense, in the form of thought experiments, is clearly a canonical philosophical activity. Often, thought experiments are designed to imaginatively tease apart features that typically or inevitably co-occur in the real world. The hope is that by imagining counterfactual possibilities - that I live in a county filled with fake barns; that I must choose which world to inhabit without knowing what role I will occupy within that world; that I have a doppelganger on Twin Earth who uses the word "water" in an environment filled with XYZ - we will be able to discern which features in the actual world are criterial for the appropriate application of philosophically interesting concepts. In order for this hope to be realized, we must ensure, first, that the author has accurately described the intended metaphysical transformation, and second, that the specified situation really does tease apart all of the philosophically significant features, isolating just the explanatorily relevant ones.

Philosophers also use thought experiments, such as the trolley problem, to present a supposedly common phenomenon in especially stark and vivid terms, thereby helping us to focus our attention on its structurally relevant features. Often, these cases are only schematically described, since their main point lies in the situation's structure. But such thought experiments can also operate in at least one of the ways literary fictions do: By describing counterfactual situations in concrete detail, they can trigger a kind of experiential acquaintance that an abstract description misses. ${ }^{21}$ Bernard Williams's (1973, 98-99) case of Jim and the Indians is a paradigmatic example of this:

Jim finds himself in the central square of a small south American town. Tied up against the wall are a row of twenty Indians, most terrified, a few defiant, in front of them several armed men in uniform. A heavy man in a sweatstained khaki shirt turns out to be the Captain in charge and, after a good deal of questioning of Jim which establishes that he got there by accident while on a botanical expedition, explains that the Indians are a random group of the inhabitants who, after recent acts of protest against the government, are just about to be killed to remind other possible protestors of the advantages of not protesting. However, since Jim is an honored visitor from another land, the Captain is happy to offer him a guest's privilege of killing one of the Indians himself. If Jim accepts, then as a mark of the special occasion, the other Indians will be let off. Of course, if Jim refuses, then there is no special occasion, and Pedro here will do what he was about to do when

21. Ichikawa and Jarvis (2009) argue that our intuitions about thought experiments are generated by the same basic principles that govern truth in fiction. 
Jim arrived, and kill them all. Jim, with some desperate recollection of schoolboy fiction, wonders whether if he got hold of a gun, he could hold the Captain, Pedro and the rest of the soldiers to threat, but it is quite clear from the set-up that nothing of the kind is going to work: any attempt at that sort of thing will mean that all the Indians will be killed, and himself. The men against the wall, and the other villagers, understand the situation, and are obviously begging him to accept. What should he do?

Here, the rich imagery (e.g., "a heavy man in a sweat-stained khaki shirt") helps us to project ourselves imaginatively into the situation, in a way that precludes the pat application of general moral principles (in particular, utilitarian principles) that might be tempting given a more abstract, schematic description.

So pretense has an established place in philosophical methodology, where this includes not just hypothetical supposition but also experiential imagination. What about metaphor? Philosophers do regularly appeal to metaphors; and the most enduring of these are repeatedly cited and elaborated because they provide an organizational template for making sense of a complex domain. ${ }^{22}$ Obvious examples include Descartes' "architectural" epistemological foundationalism; Neurath's ship of scientific knowledge; Quine's web of belief meeting the tribunal of experience; and Wittgenstein's obsessed fly trapped in a philosophical bottle. These metaphors guide our thinking about their topics in an open-ended and intuitive way, and they are not easily eliminated in favor of a point-by-point enumeration of the individual features in the focal domain to which they draw our attention-at least not until we achieve much greater independent conceptual clarity about those domains.

Perhaps because it is so complex and intangible, the mind has been particularly prone to metaphorical characterizations, from Plato's wax tablet through the Cartesian theater and Locke's blank slate, to the currently dominant metaphor of the mind as the software of the brain's hardware. Such metaphors provide us with a tractable, concrete framework for identifying, relating, and explaining important features of something which at once utterly familiar and also quite baffling. They can also suggest avenues for further investigation, by presenting important features of the framing characterization that are as yet unmatched by features in the focal topic. $^{23}$ The risk is that we will fail to notice features in the focal topic that are not matched to any features in the frame. For instance, the computer model tends to minimize the ways in which beliefs and other mental states are indeterminate,

22. Daniel Cohen $(2004,5)$ articulates precisely my distinction between the two imaginative projects of "see[ing] the world in a new light" and "imagin[ing] an entirely new world," except that he presents it as a distinction between the role of metaphor and of counterfactual reasoning within philosophy. However, Cohen also claims that "it seems safe to say that with the exception of completely formal exercise in mathematical logic, philosophy is thoroughly metaphorical" (2004, 5; cf. also Lakoff and Johnson 1999). I reject this stronger claim: metaphor is a conceptual tool that philosophers do, and I think should, employ; but it is just one tool, and much philosophical discourse is and should be literal.

23. In Camp (2006), I argue that metaphor can actually extend our expressive resources in these circumstances, enabling us to refer to properties that we lack a sufficiently robust cognitive grip to identify in literal terms. 
context-specific, and associationist, instead highlighting respects in which they are stable, discrete and rule-governed. Often the most efficient way to counteract this risk of unnoticed ignorance, especially for domains to which we lack robust independent cognitive access, is by switching to a different metaphor, one that highlights and downplays different sets of features. So, for instance, it can seem that the mind must be a lot like a general-purpose computer, until we try thinking of it instead as a pandemonium of various "demons" or sub-modules vying for attention (Dennett 1991), or as having an "enzymatic" architecture in which sub-modules use a lock-and-key matching process to identify and manipulate information before returning it to a common pool (Barrett 2005). Although these metaphors conflict with one another insofar as they identify different features of the mind as important and assign different explanations to relations among particular features, they can help us to identify possible features and explanations which we can then step back to assess directly, independently of any metaphor. ${ }^{24}$

In fact, there may even be a place within philosophy for the more complex imaginative structures exemplified by the poems in $\$ 3$. To see this, consider Judith Jarvis Thomson's (1971,48-49) case of the famous violinist. Thomson argues for the permissibility of abortion by asking us to imagine the following scenario:

You wake up in the morning and find yourself back to back in bed with an unconscious violinist. A famous unconscious violinist. He has been found to have a fatal kidney ailment, and the Society of Music Lovers has canvassed all the available medical records and found that you alone have the right blood type to help. They have therefore kidnapped you, and last night the violinist's circulatory system was plugged into yours, so that your kidneys can be used to extract poisons from his blood as well as your own. The director of the hospital now tells you, "Look, we're sorry the Society of Music Lovers did this to you - we would never have permitted it if we had known. But still, they did it, and the violinist is now plugged into you. To unplug you would be to kill him. But never mind, it's only for nine months. By then he will have recovered from his ailment, and can safely be unplugged from you." Is it morally incumbent on you to accede to this situation? No doubt it would be very nice of you if you did, a great kindness. But do you have to accede to it? What if it were not nine months, but nine years? Or longer still? What if the director of the hospital says, "Tough luck, I agree. But now you've got to stay in bed, with the violinist plugged into you, for the rest of your life. Because remember this. All persons have a right to life, and violinists are persons. Granted you have a right to decide what happens in and to your body, but a person's right to life outweighs your right to decide what happens in and to

24. Similarly, it can seem inevitable that we must think in a language-like format, insofar as our thought is systematic, productive, and rule-governed. In addition to ignoring the respects in which our thought is unsystematic and limited, this ignores the possibility that a non-sentential format could also produce systematicity. In Camp (2007), I argue that maps can also be compositional, although maps also display expressive limitations that language, and our own thought, do not. 
your body. So you cannot ever be unplugged from him." I imagine you would regard this as outrageous, which suggests that something really is wrong with that plausible-sounding argument I mentioned a moment ago.

Like Williams, Thomson includes details that go beyond a simple presentation of the case, in order to increase our imaginative engagement with the scenario. But in Williams's case the very scenario described- "just plain exactly that"-was itself the object of philosophical attention. Here, by contrast, the imagined situation is sufficiently outlandish that its interest lies only in its relation to something else: an unwanted pregnancy.

Thomson presents her example as serving the fairly minimal rhetorical purpose of demonstrating that something is structurally wrong with a traditional argument that abortion unfairly kills an innocent person. If the two situations are similar in all relevant respects but our intuitions about their permissibility differ, then the anti-abortion argument must be illicitly relying upon some implicit feature that is special to unwanted pregnancy. Construed in this minimal way, her case is an instance of the quite general philosophical strategy of demonstrating an argument's invalidity by substituting otherwise equivalent terms - a strategy that need involve no rich imaginative activity. However, I believe this simple description ignores an important part of what makes Thomson's example so rhetorically effective. The scenario is powerful because it can restructure our understanding of unwanted pregnancy: highlighting features such as the sudden deviation from the woman's life plan and deprivation of her self-determination, and ignoring features that are not exemplified by the scenario, such as biological relatedness and voluntariness. Further, Thomson's example reframes the supposed duty to continue an unwanted pregnancy in terms of an affirmative duty to aid, a duty which many people reject on independent grounds. Finally, the example's details generate a visceral emotional response, which we may then transfer onto the case of unwanted pregnancy.

Because it relies on these intuitive structures and emotional responses, the metaphor retains at least some of its "framing effect" in the face of challenges to the appropriateness of specific components of the mapping. As Moran (1989, 90-91) puts it,

Part of the dangerous power of a strong metaphor is its control over one's thinking at a level beneath that of deliberation or volition...[T]he full appreciative comprehension of a metaphor can make any subsequent denial of the point it makes seem feeble or disingenuous in much the same way that appreciative understanding of a joke can overpower any subsequent refusal of the point it makes.

A rhetorical effect that persists in the face of rational challenge sounds like the sort of thing that shouldn't have any place within philosophy. However, I think we may want to accord metaphor a legitimate place in the philosopher's toolkit. Ordinary thought in general, and moral thinking in particular, is not purely rational. Our moral judgments are often affected by emotions (Greene et al. 2001; Haidt 2001; 
Nichols and Knobe 2007); they can also can be affected, sometimes in ways outside our voluntary control, by features that we explicitly disavow as irrelevant, such as implicit racist and sexist biases (e.g., McConnell \& Leibold 2001). One reason that people may have different intuitions about unwanted pregnancy and the famous violinist case, for instance, might be that they unconsciously blame rape victims for provoking the rape. If so, then it might be legitimate to eliminate the effect of this bias by framing the situation in a way that filters out this feature.

As philosophers, we might hope that our training in rational discourse immunizes us against such emotional and prejudicial effects. But we also rely heavily on intuition, which is vulnerable to precisely these sorts of unacknowledged influences. If we insist upon confining ourselves to scrupulously rational modes of thought and discussion, then this may well have the effect of granting inappropriate influence to pre-existing biases-especially given that these biases have been demonstrated to persist even after having been rationally acknowledged to be illegitimate. Against this, harnessing the power of imagination to reconfigure our thoughts by more intuitive means may enable us to counteract these biases in a more thoroughgoing way.

More generally, both pretense and metaphor enrich the range of phenomena available for systematic philosophical reflection and analysis, and provide hints of the truth which we could not envision if we relied only on the machinery of formal inference. Insofar as philosophy seeks understanding, we need to do more than just identify a set of justified true propositions. We need to know which propositions we should pay attention to, what explanatory structures to impose upon them, and (in the moral case at least) even how we should feel about them. That is, we need something like a perspective, in the sense I have discussed here: a "way to go on" in interpreting existing data and tackling new problems. And if that is right, then we can also use tools for manipulating, transforming, and refining those perspectives. For this, metaphors, just-so stories, and other imaginatively engaged fictions may provide just the key. Pretense and metaphor are no substitute for rational argument, but they can provide grist for our argumentative mills, and spotlights into domains where we are otherwise groping in the dark.

In this paper, I have tried to suggest a richer model of the imagination, and of the mind more generally, as encompassing more than just collections of propositions represented in a certain modality and assigned to certain functional "boxes." Those contents are also structured, explained, and colored in intuitive, holistic ways. Metaphor is a powerful conceptual tool because it manipulates these intuitive structures. Where pretense imaginatively transforms what we imagine to be true in the world, metaphorical construal reconfigures how we think about what is true, by getting us to think of one thing as or in terms of something else. Having distinguished the two imaginative activities of pretense and seeing-as, we can also see that they interact in complex ways in literature and even in philosophy. A poem like Simic's transports us to absurdly surreal territory from the start, but then hints that the real absurdity lies our own insistence on living life as if it were ordinary. Stafford's poem becomes a metaphor for how to live one's life, even though its language is largely literal. And Wordsworth's poem describes an innocuous and familiar scene, but gradually draws us toward a radical revamping of our concep- 
tion of nature and our place in it. Insofar as poems like these help us to see more clearly how things might really be and how we should act in the world, their aims are not so far removed from philosophy. And insofar as philosophy takes us on detours through wildly counterfactual terrain and employs metaphors and fictions to reconfigure our understanding of what really is, its methods are not as far removed from poetry as we might initially have thought. ${ }^{25}$

\section{REFERENCES}

Barrett, H. Clark. 2005. "Enzymatic Computation and Cognitive Modularity." Mind \& Language 20: 259-87.

Black, Max. 1962. "Metaphor." Proceedings of the Aristotelian Society 55: 273-94.

Booth, Stephen. 1969. An Essay on Shakespeare's Sonnets. New Haven, CT: Yale University Press. Brooks, Cleanth. 1947. "The Heresy of Paraphrase.” In The Well Wrought Urn. New York: Harcourt Brace.

Camp, Elisabeth. 2003. Saying and Seeing-as: The Linguistic Uses and Cognitive Effects of Metaphor, dissertation. University of California, Berkeley.

_. 2006. "Metaphor and That Certain 'Je Ne Sais Quoi'." Philosophical Studies 129: 1-25.

. 2007. "Thinking with Maps." In Philosophical Perspectives 21: Philosophy of Mind, ed. John Hawthorne, 145-82. Oxford: Wiley-Blackwell.

—. 2008. "Showing, Telling, and Seeing: Metaphor and 'Poetic' Language." The Baltic International Yearbook of Cognition, Logic, and Communication, vol. 3: A Figure of Speech [Online], ed. Elisabeth Camp.

Cohen, Daniel. 2004. Arguments and Metaphors in Philosophy. Dallas, TX: University Press of America.

Cohen, Ted. 1976. "Notes on Metaphor." Journal of Aesthetics and Art Criticism 34: 249-59.

Currie, Gregory. 1995. "The Moral Psychology of Fiction.” Australian Journal of Philosophy 73: $250-59$.

- 1997. "The Paradox of Caring: Fiction and the Philosophy of Mind." In Emotion and the Arts, ed. Mette Hjort and Sue Laver. New York and Oxford: Oxford University Press.

Danto, Arthur. 1981. The Transfiguration of the Commonplace: A Philosophy of Art. Cambridge, MA: Harvard University Press.

Davidson, Donald. 1978. "What Metaphors Mean.” Critical Inquiry 5: 31-47.

Dennett, Daniel. 1991. Consciousness Explained. Boston, MA: Little, Brown.

Gendler, Tamar Szabó. 2000. “The Puzzle of Imaginative Resistance.” Journal of Philosophy 97: $55-81$.

Greene, Joshua, Sommerville, Brian, Nystrom, Leigh, Darley, John, and Cohen, Jonathan. 2001. “An fMRI Investigation of Emotional Engagement in Moral Judgment.” Science 293: 2105-8.

Haidt, Jonathan. 2001. "The Emotional Dog and its Rational Tail: A Social Intuitionist Approach to Moral Judgment." Psychological Review 108: 814-34.

Hills, David. 1997. "Aptness and Truth in Verbal Metaphor." Philosophical Topics 25: 117-53.

Ichikawa, Jonathan, and Jarvis, Benjamin. 2009. "Thought-Experiment Intuitions and Truth in Fiction." Philosophical Studies 142(2): 221-46.

Kieran, Matthew. 2003. "Forbidden Knowledge: The Challenge of Immoralism." In Art and Morality, ed. José Luis Bermudez and Sebastian Gardner. London: Routledge.

Lakoff, George, and Johnson, Mark. 1999. Philosophy in the Flesh: The Embodied Mind and Its Challenge to Western Thought. New York: Basic Books.

Levin, Samuel. 1979. "Standard Approaches to Metaphor and a Proposal for Literary Metaphor." In Metaphor and Thought, ed. Andrew Ortony. Cambridge: Cambridge University Press.

25. Thanks to Richard Wollheim and, more recently, Dmitri Tymoczko for extensive discussion. 
1988. Metaphoric Worlds: Conceptions of a Romantic Nature. New Haven, CT: Yale University Press.

McConnell, Allen and Leibold, Jill. 2001. "Relations among the Implicit Association Test, Discriminatory Behavior, and Explicit Measures of Racial Attitudes." Journal of Experimental Social Psychology 37: 435-42.

Moran, Richard. 1989. "Seeing and Believing: Metaphor, Image, and Force." Critical Inquiry 16: $87-112$.

- 1994. "The Expression of Feeling in Imagination." Philosophical Review 103: 75-106.

Nanay, Bence. 2004. "Taking Twofoldness Seriously: Walton on Imagination and Depiction." The Journal of Aesthetics and Art Criticism. 62: 285-89.

Nichols, Stephen, and Knobe, Joshua. 2007. "Moral Responsibility and Determinism: The Cognitive Science of Folk Intuitions." Nous 41: 663-85.

Novitz, David. 1987. Knowledge, Fiction, and Imagination. Philadelphia: Temple University Press.

Robinson, Jenefer. 2005. Deeper than Reason: Emotion and Its Role in Literature, Music, and Art. New York: Oxford University Press.

Searle, John. 1969. Speech Acts. Cambridge: Cambridge University Press.

Shakespeare, William. 1609/1997. "Sonnet 73." In The Riverside Shakespeare, 2nd edn, ed. G. Blakemore Evans et al. New York: Houghton Mifflin Co.

Simic, Charles. 1977. "Eyes Fastened with Pins." In Charon's Cosmology: Poems. New York: Braziller.

Stafford, William. 1977. "A Story that Could Be True." In Stories That Could Be True: New and Collected Poems. New York: Harper and Row.

Thomson, Judith Jarvis. 1971. “A Defense of Abortion.” Philosophy \& Public Affairs 1: 47-66.

Walton, Kendall. 1990. Mimesis as Make Believe. Cambridge, MA: Harvard University Press. 1993. "Metaphor and Prop-Oriented Make-Believe." European Journal of Philosophy 1: $39-57$.

2000. "Existence as Metaphor?" In Empty Names, Fiction, and the Puzzles of Existence, ed. Anthony Everett and Thomas Hofweber. Stanford, CA: Center for the Study of Language and Information.

Williams, Bernard. 1973. A Critique of Utilitarianism. Cambridge: Cambridge University Press.

Wollheim, Richard. 1980. "Seeing-as, Seeing-in, and Pictorial Representation." In Art and its Objects: With Six Supplementary Essays, 2nd ed. Cambridge: Cambridge University Press.

Wordsworth, William. 1804/1967. "I Wandered Lonely as a Cloud." In English Romantic Writers, ed. David Perkins. New York: Harcourt Brace Jovanovich.

Yablo, Steven. 2001. "Go Figure: A Path Through Fictionalism." Midwest Studies in Philosophy 25: 72-102. 